\title{
TEMA 9-2016: Dependencia a tabaco y su tratamiento
}
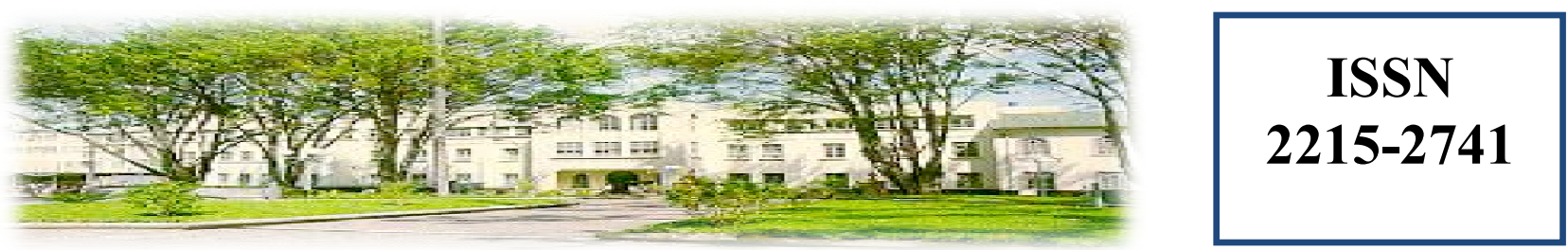

Hospital San Juan de Dios, San José, Costa Rica. Fundado en 1845

$\begin{array}{ll}\text { Recibido: } & 10 / 12 / 2015 \\ \text { Aceptado: } & 29 / 12 / 2015\end{array}$

Dra. Sofía Sandí Brenes 1

Dr. Luis Sandí Esquivel 2

1 Médico General. Correo electrónico: drasofiasandi@gmail.com

2 Médico Especialista en Psiquiatria. IAFA. Correo electrónico: leduardo56@gmail.com

\section{RESUMEN}

El tabaco es una de las mayores amenazas para la salud pública que ha tenido que afrontar el mundo. Se le atribuyen aproximadamente 6 millones de muertes al año ${ }^{(1)}$. Es además, la principal causa prevenible de mortalidad, y aquellas personas que dejan de fumar disminuyen el riesgo de desarrollar y potencialmente morir por enfermedades relacionadas al tabaco ${ }^{(2)}$. Los avances en la investigación científica y la experiencia clínica acumulada en el campo del tabaquismo, hacen que hoy en día existan, basados en la evidencia, excelentes tratamientos y estrategias para ayudar a los fumadores a dejar de fumar ${ }^{(3)}$.

\section{PALABRAS CLAVE}

Tabaco, nicotina, fumado, dependencia, tratamiento.

\begin{abstract}
Tobacco is one of the greatest public health threats the world has ever faced. Currently, the annual death toll is approximately 6 million people. It is also the leading preventable cause of mortality, and those individuals who quit smoking are less likely to develop, and potentially die due to tobacco related illnesses. The advances in clinical experience and scientific investigation in the field of tobacco consumption, make it possible that today, based on evidence, excellent treatment methods and strategies are readily available for those who wish to quit smoking.
\end{abstract}

\section{KEY WORDS}

Tobacco, nicotine, smoking, dependence, treatment. 


\section{INTRODUCCIÓN}

Globalmente, el uso de tabaco causó la muerte de 100 millones de personas en el siglo 20, cifra superior a todas las muertes de la primera y segunda guerra mundial combinadas. Si el patrón de fumado actual continúa, el número de muertes relacionadas a tabaco en el siglo 21 será cercana a 1 billón de personas. El uso de tabaco aumenta el riesgo de muerte por muchas enfermedades; cáncer, cardiopatía isquémica, enfermedad pulmonar obstructiva crónica y accidente cerebrovascular entre las más comunes. El cáncer de pulmón es la principal causa de muerte por cáncer a nivel mundial, causando aproximadamente 1.4 millones de muertes en el año 2008, y al menos $80 \%$ de las muertes por cáncer de pulmón eran atribuibles al fumado.

El tabaco no solamente causa enfermedad, en aquellos pacientes que persisten fumando a pesar de padecer enfermedad coronaria, cáncer u otras enfermedades, hay un aumento significativo del riesgo de muerte comparado con pacientes que padecen las mismas enfermedades y que nunca han fumado, o que dejaron de fumar luego de haber sido diagnosticados con la enfermedad. Aún en aquellos que fuman 10 cigarrillos o menos por día, la expectativa de vida es en promedio 5 años menor y el riesgo de cáncer pulmonar es hasta 20 veces mayor que en aquellos que nunca han fumado ${ }^{(4)}$.

\section{Epidemiología}

Al consumo de tabaco se le atribuyen aproximadamente 6 millones de muertes anuales, de las cuales 5 millones son consumidores directos y más de 600000 son no fumadores expuestos al humo ajeno. Casi el $80 \%$ de los más de mil millones de fumadores que hay en el mundo viven en países de ingresos bajos o medios, donde es mayor la carga de morbilidad y mortalidad asociada al tabaco ${ }^{(1)}$.

En Costa Rica, según los datos de la Encuesta de Hogares del 2010, la prevalencia de vida de consumo de tabaco en la población entre los 12 y 70 años fue un $24,8 \%$, del cual $30,7 \%$ corresponde a hombres y $18,7 \%$ a mujeres. La estimación total de fumadores activos (fumadores del último mes) fue de 434.000 , de los cuales 297.000 corresponden a hombres y 137.000 a mujeres ${ }^{(5)}$.
Aproximadamente $70 \%$ de los fumadores refieren que quieren dejar de fumar, y más del $50 \%$ intentó dejar de fumar en el último año. Sin embargo, sólo de un 3-6\% de los fumadores que intentaron cesar el consumo sin ningún tipo de ayuda o asesoramiento se mantienen abstinentes un año después. Solamente un $32 \%$ de los fumadores que intentan cesar buscan ayuda y un porcentaje aún menor utiliza los tratamientos más efectivos. Con el uso de un tratamiento óptimo, las cifras de abstinencia a un año plazo luego de un primer intento para dejar de fumar pueden exceder el $30 \%{ }^{(2)}$

Una elevada proporción de los pacientes psiquiátricos fuman. Lo hacen aproximadamente el 50\% de los pacientes psiquiátricos ambulatorios, el $70 \%$ de los ambulatorios con trastorno bipolar I, casi el $90 \%$ de los ambulatorios con esquizofrenia y el $70 \%$ de los pacientes con trastornos por consumo de sustancias. Además, los datos indican que los pacientes con trastornos depresivos o de ansiedad tienen menos éxitos en sus intentos de abandonar el tabaquismo en comparación con otros individuos ${ }^{(6)}$.

\section{Fumado involuntario}

Fumador involuntario es toda persona que inhala aire contaminado con sustancias producidas por la combustión del tabaco. El fumado involuntario o fumado de segunda mano, ocurre cuando un no fumador se expone al humo que exhala el fumador (corriente principal) y al humo que sale del cigarrillo (corriente lateral). La exposición a la corriente de humo lateral se relaciona con la inhalación de humo sin haber pasado por un filtro, ya sea del cigarrillo o del pulmón del fumador; contiene una mezcla nociva de gases y partículas de alquitrán carcinogénicas que responden aproximadamente al $85 \%$ de la contaminación atmosférica en interiores ${ }^{(3)}$.

La exposición a humo de segunda mano puede causar muchas de las mismas enfermedades que el fumado activo. Aumenta el riesgo de cáncer pulmonar en un $30 \%$ y de enfermedad coronaria en un 25\%. En el año 2010, murieron 600000 no fumadores debido a exposición a humo de segunda mano. Cardiopatía isquémica, infecciones del tracto respiratorio inferior, asma y cáncer de pulmón son las causas de muerte más comunes relacionadas a humo de segunda mano. La nicotina y otros compuestos del tabaco se acumulan en diversas superficies (ropa, muebles, paredes y 
vehículos) y pueden permanecer ahí durante varios meses, y aún después de que las superficies hayan sido limpiadas ${ }^{(4)}$

\section{DISCUSIÓN}

La nicotina es un alcaloide natural que se encuentra primariamente en el tabaco. Un cigarrillo contiene de 10-15 mg de nicotina, de los cuales el fumador absorbe en promedio $1 \mathrm{mg}$.

\section{Farmacocinética de la nicotina}

El pico de la concentración plasmática de nicotina durante el fumado es de $10-50 \mathrm{ng} / \mathrm{mL}$, del cual el $5 \%$ está unida a proteínas. La vida media es en promedio de 2 horas. Aproximadamente $80-90 \%$ de la nicotina es metabolizada en pulmón, hígado y riñón; el principal metabolismo es la cotinina, que tiene una concentración en plasma 10 veces mayor que la nicotina. La vida media de la cotinina es de 15 a 20 horas y es utilizada como un biomarcador de exposición a la nicotina. Aproximadamente $17 \%$ de la nicotina se excreta sin ningún cambio por medio de la orina ${ }^{(7)}$

\section{Consideraciones genéticas}

La variabilidad interindividual en las concentraciones plasmáticas de nicotina y cotinina es considerable durante el fumado, aún en individuos que están utilizando dosis similares de nicotina. La nicotina es metabolizada primariamente por la enzima hepática CYP2A6. Se han descrito variantes del gen CYP2A6, muchas de las cuales están asociadas con un metabolismo más lento de la nicotina. En individuos en los cuales se han descrito deleciones en el gen CYP2A6, la nicotina se metaboliza más lentamente y se genera poca cotinina. Estas variantes genéticas asociadas con un metabolismo lento son más prevalentes en asiáticos y personas de raza negra. Las personas que genéticamente son metabolizadores lentos tienden a fumar menos cigarrillos por día y son capaces de cesar el uso de cigarrillos más fácilmente que aquellos con un metabolismo rápido.

La nicotina actúa en los receptores nicotínicos de acetilcolina, que están constituídos por 5 subuni- dades. Los receptores que contienen las subunidades $\alpha_{4} \beta_{2}$ median la dependencia a nicotina. Aquellos que contienen las subunidades $\alpha_{3} \beta_{4}$ median los efectos cardiovasculares de la nicotina $^{(7)}$.

\section{Consecuencias del fumado}

El humo del tabaco contiene más de 7000 químicos, cientos de los cuales son tóxicos y afectan negativamente casi todos los órganos. Los niños cuyas madres fumaron durante el embarazo tienen un riesgo aumentado de enfermedades congénitas, cáncer, enfermedades respiratorias y muerte súbita. Tanto el fumado activo como el de segunda mano aumentan el riesgo de enfermedad cardiovascular promoviendo aterosclerosis, formación de coágulos y otros mecanismos. En el humo de tabaco se encuentran al menos 69 carcinógenos. El fumado incrementa el riesgo de muerte por enfermedad isquémica más de 2.5 veces y de muerte por cáncer pulmonar y enfermedad pulmonar crónica 20 veces ${ }^{(4)}$.

El fumado causa daño y enfermedad a la mayoría de los órganos, entre sus consecuencias a nivel de cabeza y cuello cabe destacar: cataratas, ceguera (por degeneración macular), accidente cerebrovascular, cáncer de cavidades nasales y senos paranasales, rinosinusitis crónica, alteración del olfato, enfermedad periodontal, pérdida de piezas dentales, caries, cáncer de labios, boca, laringe y faringe, alteración del sentido del gusto, mal aliento, cáncer bronquial, pulmonar y traqueal, enfermedad pulmonar obstructiva crónica, asma, tos crónica, trombosis coronaria, aterosclerosis. A nivel de tórax y abdomen: cáncer esofágico, gástrico, colónico, hepático y pancreático, úlcera péptica, riesgo aumentado de cáncer de mama. También está involucrado en casos de fertilidad reducida, impotencia, enfermedad vascular periférica, trombosis venosa profunda, osteoporosis, entre otras ${ }^{(4)}$.

\section{Dependencia psicológica y física}

Ladependencia al tabaco debe ser considerada como una alteración médica crónica, con periodos de abstinencia y recurrencias en el tiempo. El concepto de enfermedad se fundamenta en las alteraciones neurofisiológicas, estructurales y funcionales, que provocan la continua búsqueda de la droga. Las modificaciones o ajustes neu- 
roadaptativos producidos por la nicotina son permanentes y constituyen la base neurobiológica de la dependencia al tabaco.

La dependencia psicológica se refiere al conjunto de asociaciones aprendidas entre el fumar y determinadas circunstancias internas y externas asociadas al fumado. El cigarrillo se incorpora a la personalidad del fumador, forma parte de sus gestos, costumbres y autoimagen, haciendo del fumar parte de un estilo de vida.

Por otra parte, la dependencia física se refiere a un estado de neuroadaptación producido por la administración repetida de una sustancia, que determina la necesidad de continuar su consumo, para evitar el síndrome originado por su privación, conocido como síndrome de supresión. La nicotina es la principal sustancia responsable de la dependencia química al tabaquismo, es una sustancia psicoactiva que ejerce su efecto a nivel del sistema nervioso central y actúa como un reforzador positivo por su efecto psicoestimulante y relajante. El efecto estimulante se debe a un aumento en la liberación de neurotransmisores, principalmente dopamina, en los sistemas de recompensa cerebrales, que están formados básicamente por el área tegmental ventral (ATV) y el núcleo accumbens. Estas vías tienen proyecciones con la corteza prefrontal, la cual está relacionada con funciones mentales superiores. Tanto en el ATV como en el núcleo accumbens existen receptores nicotínicos de acetilcolina, que se encuentran además ganglios autónomos, médula suprarrenal y uniones neuromusculares. Los receptores más abundantes en el sistema nervioso central, específicamente en el sistema de recompensa son los $\alpha_{4} \beta_{2}$. Cuando la nicotina entra en contacto y ocupa estos receptores en el sistema de recompensa, se produce una descarga dopaminérgica que se traduce en una experiencia de placer y bienestar, lo cual se conoce como un refuerzo positivo, es decir, el fumador busca repetirla dada lo agradable de la experiencia ${ }^{(8)}$.

La dependencia a la nicotina es un trastorno de tipo biopsicosocial, en el que interactúan de manera compleja y profunda, adaptaciones neuropsicobiológicas con intensos condicionamientos o aprendizajes asociativos. Paralelamente al impacto neuroquímico de la nicotina, ocurre un fenómeno absolutamente personal arraigado en las costumbres, actitudes, sentimientos, necesidades y emociones del fumador, que se van ligando de una manera profunda y compleja a cada acto de fumar ${ }^{(8)}$

\section{Síndrome de supresión}

Una vez que se desarrolla la dependencia a la nicotina, el cuerpo se ha adaptado a mantener niveles estables de nicotina durante el día. La reducción o ausencia de nicotina provoca un desbalance en el sistema noradrenérgico y todos los demás circuitos neuronales interconectados, que se manifiesta en una multiplicidad de signos y síntomas que aparecen a las pocas horas. La presencia de estos síntomas es una clara manifestación de dependencia física y puede ser tan intensa que se convierte en el principal obstáculo para poder dejar de fumar. Los síntomas más importantes del síndrome de supresión al tabaco son: insidia (desesperación por fumar), estado de ánimo disfórico o depresivo, irritabilidad, inquietud, ansiedad, insomnio, frustración, dificultad para concentrarse, aumento del apetito y constipación ${ }^{(8)}$.

Los síntomas generalmente llegan a su tope en los primeros 3 días y decaen en el transcurso de las siguientes 3 a 4 semanas ${ }^{(9)}$. Durante meses y años puede permanecer el deseo de fumar, pero la insidia es una exclusiva manifestación de supresión física.

\section{Tratamiento}

La mejor estrategia para dejar de fumar, es un enfoque multimodal que incluya estrategias conductuales y farmacológicas bajo la premisa de que el paciente necesita ayuda y consejo. La intervención breve para dejar de fumar se fundamenta en 5 acciones, conocidas como las $5 \mathrm{~A}$ : averiguar, aconsejar, analizar, asistir y acordar un tratamiento ${ }^{(3)}$

Averiguar: Se debe indagar la frecuencia de uso, los productos usados, el grado de dependencia nicotínica, la historia de intentos de cese previos (incluyendo los métodos usados y su efectividad) y la disposición del fumador para cesar. En aquellos individuos quienes no usan productos del tabaco, se debe preguntar por la exposición a humo de segunda mano ${ }^{(2)}$.

Aconsejar: De manera fuerte, clara y personalizada se debe alentar a todo fumador a dejar el cigarrillo ${ }^{(3)}$. Aunque no todo paciente al que se aconseje dejar de fumar está preparado para considerar el cese, hay evidencia clara de que una intervención de consejería breve para dejar 
de fumar por parte del médico en cada cita puede incrementar las tasas de abstinencia ${ }^{(2)}$.

Analizar: Posterior al consejo, el clínico debe evaluar la voluntad del paciente para realizar una intento de cese. Los fumadores difieren en su disposición para dejar de fumar, y entender la perspectiva del fumador es esencial para proveer asistencia útil. Las etapas de cambio fueron desarrolladas para describir el proceso por el cual el cambio en la conducta ocurre. Se identifican 5 etapas por las cuales los fumadores progresan del fumado a la abstinencia: precontemplación (no listo para el cese), contemplación (considerando un intento de cese), preparación (planea activamente el cese), acción (activamente envuelto en el intento de cese) y mantenimiento (logró el cese) ${ }^{(2)}$.

Asistir: Cuando el paciente está motivado para dejar de fumar, se les debe proveer acceso a los recursos apropiados que puedan ayudarlo en el proceso. Se debe indagar sobre las experiencias previas en intentos de cese, los métodos que fueron utilizados y el grado de éxito alcanzado, lo cual es importante para poder guiar las recomendaciones para el próximo intento de cese. El médico también debe asesorar al paciente a anticipar las barreras que le impidan cesar y aprender a manejarlas ${ }^{(2) .}$

Acordar: Una cita de seguimiento debe ser programada una semana después de la fecha del cese, y de manera regular en los primeros tres meses y luego más distante hasta por un mínimo de 6 meses e idealmente un año.

Puntos importantes que se deben cubrir incluyen dar reforzamiento positivo al paciente por haber logrado el cese y alentarlo a continuar en abstinencia, identificar los problemas que ha encontrado en el proceso y anticipar retos que estén por venir, evaluar el uso de la medicación, problemas y eficacia, y recordar al paciente las otras fuentes de apoyo disponibles.

\section{Farmacología}

La farmacoterapia para la cesación del fumado ayuda a reducir los síntomas del síndrome de supresión, lo que facilita que el fumador pueda desprenderse del cigarrillo. Los principales medicamentos que han demostrado eficacia para ayudar en la cesación incluyen terapia de remplazo nicotínico (TRN), vareniclina y bupropión. Con pocas excepciones, la escogencia de la medicación de primera línea se basa generalmente en la preferencia del paciente luego de comentarlo con su médico.

Terapia de reemplazo nicotínico: El objetivo de la terapia de reemplazo de nicotina es proveer nicotina al fumador sin utilizar tabaco y de esta forma aliviar los síntomas del síndrome de supresión. Las diferencias en la biodisponibilidad de los productos de reemplazo nicotínico justifican la combinación de la TRN. El parche de nicotina, de acción larga y comienzo lento, es la TRN primaria para controlar los síntomas de supresión. Combinar un producto de TRN de acción corta (chicles, caramelos inhalador, spray nasal) en caso necesario, ayuda a controlar la insidia y los síntomas de supresión que se manifiestan a lo largo del día. La combinación de la TRN es más efectiva que las terapias con un único producto. La dosis de la TRN se titula gradualmente de acuerdo a la severidad de los síntomas de supresión. En general, se recomienda el uso de esta terapia durante 2 a 3 meses luego del cese, aunque es aceptable extender este periodo en pacientes con un alto riesgo de recaída o que han realizado múltiples intentos para dejar de fumar ${ }^{(10)}$. Las TRN más frecuentemente utilizadas son los parches y chicles de nicotina.

Parche transdérmico de nicotina: La presentación de los parches depende de la casa farmacéutica, por ejemplo con parches de 15,10 y $5 \mathrm{mg}$ el esquema de dosificación se puede dividir de la siguiente manera:

\begin{tabular}{|c|l|c|}
\hline Programa de 3 etapas & \multicolumn{2}{|c|}{ Fumadores de más de 10 cigarrillos } \\
I Etapa & Parche de $15 \mathrm{mg}$ por día & 8 semanas \\
\hline II Etapa & Parche de $10 \mathrm{mg}$ por día & 2 semanas \\
\hline III Etapa & Parche de $5 \mathrm{mg}$ por día & 2 semanas \\
\hline
\end{tabular}

\begin{tabular}{|c|c|c|} 
Programa de 2 etapas & \multicolumn{2}{|c|}{ Fumadores de 10 cigarrillos o menos } \\
\hline II Etapa & Parche de $10 \mathrm{mg}$ por día & 8 semanas \\
\hline II Etapa & Parche de $5 \mathrm{mg}$ por día & 2 semanas \\
\hline
\end{tabular}

Existen parches de 16 y 24 horas. El parche debe ser colocado en una zona de la piel libre de vello, limpia y seca, y se debe cambiar el sitio de colocación cada día. Entre los efectos secundarios más frecuentes se encuentran: cefalea, mareo, 
malestar estomacal, debilidad, visión borrosa, insomnio, sueños vívidos, prurito leve o ardor en el área de aplicación. Contraindicados en pacientes con enfermedad cardiovascular severa, enfermedad vascular cerebral, enfermedades de la piel que puedan complicar la aplicación del parche, mujeres embarazadas o amamantando ${ }^{(8)}$

Chicles de nicotina: En este producto, la nicotina se libera por medio de la masticación, se absorbe al torrente sanguíneo por medio de la mucosa oral y produce así un alivio inmediato de los síntomas de supresión. Se encuentran en presentaciones de $2 \mathrm{mg}$ y $4 \mathrm{mg}$ por pieza. El de $2 \mathrm{mg}$ provee al paciente $0.86 \mathrm{mg}$ de nicotina, y el de 4 $\mathrm{mg}$ provee $1.4 \mathrm{mg}$ de nicotina ${ }^{(3)}$.

La dosis de $4 \mathrm{mg}$ se recomienda para fumadores quienes consumen 25 o más cigarrillos por día, mientras que los de $2 \mathrm{mg}$ se recomiendan para aquellos que fuman menos de 25 cigarros por día (10).

Se le debe instruir al paciente a mascar un chicle cada 1-2 horas durante las primeras 8 semanas y posteriormente ampliar el intervalo de tiempo entre cada chicle como se muestra a continuación:

\begin{tabular}{|c|c|c|}
\hline Semana & Cantidad de chicles & Intervalo \\
\hline $1-8$ & 1 & $1-2$ horas \\
\hline $9-10$ & 1 & 4 horas \\
\hline $11-12$ & 1 & $6-8$ horas \\
\hline
\end{tabular}

El chicle de nicotina no debe ser masticado como un chicle convencional, sólo debe ser masticado cuando se necesita que libere nicotina. El chicle se mastica despacio hasta que se presente un hormigueo ligero o sabor picante en la boca, en este momento debe ser colocado entre la mejilla y la encía para que repose; al desaparecer la sensación se vuelve a masticar. No se debe mantener en la boca por más de 30 minutos ${ }^{(3)}$.

Se deben evitar las bebidas ácidas antes y durante el uso del chicle, ya que bajan el $\mathrm{pH}$ oral y causan que la nicotina se ionice y su absorción se reduzca ${ }^{(10)}$.

Los efectos secundarios incluyen úlceras bucales, hipo, mal sabor, dispepsia, dolor mandibular. Se debe tener precaución en pacientes con enfermedad cardiovascular; se debe evitar durante las dos semanas siguientes a un infarto o en quienes padecen de arritmias graves. Tratar de evitarlo en mujeres embarazadas o lactando. Se contraindican en pacientes con enfermedades de la articulación temporomandibular, inflamación orofaríngea, problemas dentales o trabajo dental reciente $^{(8)}$

Con la terapia de reemplazo se alcanzan nicotinemias de 10-15 ng/ml, generalmente un 45 a un $60 \%$ de lo que obtiene el fumador con su dosis habitual de cigarrillos. Dada la gran variabilidad de las nicotinemias en los fumadores, se busca alcanzar aproximadamente un 50\% de la dosis habitual del fumador. Si los síntomas de supresión no son aliviados, probablemente la persona necesita una dosis mayor. El tratamiento debe ser ajustado de acuerdo a la severidad de la dependencia a la nicotina, experiencia previa con TRN, intentos previos de cese y respuesta a la dosis inicial $^{(3) \text {. }}$

Vareniclina: Es un agonista parcial de la subunidad $\alpha_{4} \beta_{2}$ del receptor nicotínico de acetilcolina. Este medicamento provee ayuda para lograr el cese de dos formas: como un agonista parcial, se une y produce una estimulación parcial del receptor nicotínico $\alpha_{4} \beta_{2}$ y de esta forma reduce los síntomas de supresión nicotínica. En segundo lugar, como vareniclina se une con gran afinidad a la subunidad $\alpha_{4} \beta_{2}$ del receptor, impide que la nicotina del humo del tabaco se una a dicho receptor y de esta manera reduce los aspectos de recompensa que se derivan del fumado.

Este medicamento no presenta metabolismo hepático, y por tanto tiene pocas interacciones con otras drogas. Se excreta casi completamente por riñón, por lo que requiere ajuste de dosis en pacientes con insuficiencia renal ${ }^{(10)}$

El tratamiento con vareniclina se inicia una semana antes de la fecha de cese establecida. Existen comprimidos de $0.5 \mathrm{mg}$ y $1 \mathrm{mg}$.

Dosificación:

- Día 1 a 3: un comprimido de $0.5 \mathrm{mg}$ en la noche.

- Día 4 a 7: un comprimido de $0.5 \mathrm{mg}$ en la mañana y otro en la noche.

- Día 8: es el día de cese de fumado y se inicia dosis de $1 \mathrm{mg}$ dos veces al día, uno en la mañana y otro en la noche.

Duración: 12 semanas, tratamientos de mayor duración tienen mejores resultados ${ }^{(8)}$

Los efectos secundarios incluyen náusea, flatulencia, dispepsia, insomnio, sueños vívidos, 
cefalea y fatiga. El efecto secundario más frecuente es la náusea, la cual se reduce tomando el medicamento con suficiente agua ${ }^{(3)}$.

Vareniclina podría presentar serios efectos secundarios neuropsiquiátricos en algunos pacientes, sin embargo la naturaleza y magnitud de este riesgo no ha sido bien definida. Se recomienda tomar una historia psiquiátrica detallada previo a prescribir la droga, y evitarla en pacientes con patología psiquiátrica inestable o historia previa de ideación suicida ${ }^{(10)}$.

Bupropión: Es un medicamento comercializado inicialmente como antidepresivo, que en la fase de investigación se descubrió que ayudaba a los pacientes a dejar de fumar. Funciona como un inhibidor de la recaptación de dopamina y noradrenalina, lo que explica su efecto en los mecanismos centrales de la dependencia y abstinencia al tabaco. Los estudios demuestran que favorece el incremento de la dopamina en el núcleo accumbens, lo que le confiere un papel de agonista dopaminérgico, efecto similar a la nicotina. Además, bupropión inhibe la acción de las neuronas noradrenérgicas en el locus ceruleus, por lo que alivia el síndrome de supresión. Por un mecanismo no conocido, produce además inapetencia al cigarrillo ${ }^{(3)}$.

Bupropión se encuentra en presentaciones de comprimidos de $150 \mathrm{mg}$ XL y $300 \mathrm{mg}$ XL. El tratamiento se inicia 2 semanas antes del día del cese. Dosificación recomendada:

- 150 mg XL en la mañana por 3 días.

- 300 mg XL en la mañana por 12 días.

- Decimoquinto día: es el día del cese del fumado, se continúa con $300 \mathrm{mg}$ XL en la mañana.

Duración: 12 semanas. Es conveniente que una vez que se llegue al final del tratamiento, se suspenda poco a poco. Se puede utilizar hasta por seis meses. El uso prolongado reduce el riesgo de recaídas. Se puede utilizar por seis meses o más, en caso de buenos resultados antidepresivos o con la regulación del peso.

Los efectos secundarios incluyen insomnio, boca seca, inestabilidad, reacciones alérgicas (erupciones cutáneas, urticaria), crisis epilépticas, taquicardia, náusea y vómito. Se contraindica en pacientes con historias de convulsiones (bupropión disminuye el umbral convulsivo), trastornos de alimentación, uso de inhibidores de la MAO, hipersensibilidad a sus productos activos ${ }^{(8)}$.

\section{Terapia combinada}

Si no se obtienen buenos resultados con bupropión, se puede combinar con terapia de reemplazo, así como con vareniclina. Por el efecto antagonista en los receptores nicotínicos que produce vareniclina, no es conveniente combinarlo con terapia de reemplazo. Con cualquiera de los psicofármacos para dejar de fumar se puede asociar el uso de ansiolíticos para la ansiedad o para los problemas con el sueño ${ }^{(3)}$.

Meta-análisis de estudios clínicos han demostrado que la combinación de tratamiento farmacológico con terapias de apoyo y consejería producen mejores resultados en las tasas de cese.

A los pacientes que se encuentren listos y motivados para dejar de fumar, se les debe ofrecer asistencia para el cese que incluye el tratamiento farmacológico y el apoyo terapéutico. La clave para lograr un cese exitoso es preparar al fumador con la mayor cantidad de información posible sobre lo que podría esperar durante el intento de cese, incluyendo las expectativas sobre el síndrome de supresión. Los programas de consejería efectivos generalmente utilizan técnicas cognitivo-conductuales que proveen consejos prácticos para evitar desencadenantes y lidiar con situaciones que inciten al paciente a fumar.

En los pacientes resistentes a dejar de fumar, una entrevista motivacional puede ser usada para explorar los sentimientos, creencias, ideas y valores con respecto al tabaco que tiene el paciente. El modelo de las 5 Rs brinda motivación para dejar de fumar en dichos pacientes, con intervenciones breves basadas en la entrevista motivacional ${ }^{(11)}$.

- Explicar la relevancia personal de la cesación.

- Informar acerca de los riesgos del tabaquismo.

- Comentar las recompensas del cese.

- Identificar las resistencias para el abandono.

- Repetir aspectos de esta conversación en cada visita ${ }^{(3)}$.

\section{Recaída}

En el tanto la dependencia al tabaco es una enfermedad crónica, la probabilidad de recaída es alta y no necesariamente refleja un fracaso del terapeuta o del paciente. El riesgo es mucho más alto en el momento que el paciente deja de fumar, disminuye un poco la primera semana y a los tres meses o más, el riesgo es mucho menor. 
Independientemente el tipo de tratamiento que se utilice para dejar de fumar, la mayoría de los fumadores tienden a recaer en los primeros tres meses posteriores al cese, por lo tanto es necesario desarrollar estrategias que prevengan y minimicen este riesgo ${ }^{(8) .}$

Una excelente estrategia para disminuir el riesgo de recaída es mantener contacto con el paciente y vigilar el proceso de recuperación por lo menos durante un año.

\section{CONCLUSIONES}

La dependencia al tabaco es una enfermedad crónica, para la cual se encuentran disponibles múltiples opciones de tratamiento, a las cuales todo fumador tiene derecho a recibir. Es de suma importancia siempre asociar el tratamiento farmacológico a terapias de apoyo ya sean individuales o grupales para conseguir una mayor eficacia.

El médico debe siempre aconsejar a los fumadores a que traten de cesar el fumado, y estar debidamente capacitado para brindar todo el apoyo que el paciente necesite para lograrlo.

\section{BIBLIOGRAFÍA}

1. Organización Mundial de la Salud. Tabaco. Nota descriptiva N.339. Julio, 2015. En: http://www.who.int/mediacentre/factsheets/f s339/es/

2. Rigotti N. Overview of smoking cessation management in adults. Uptodate, 2015.

3. Sandí L, Molina D. Guía de intervención para el tratamiento de la dependencia al tabaco. Instituto sobre Alcoholismo y Farmacodependencia, 2013.

4. Ericksen M Mackay J Schluger Islami F Drope J. The tobacco atlas. 5ta edición, 2015.

5. Fonseca S. (2012). Consumo de drogas en Costa Rica. Encuesta nacional 2010. Consumo de tabaco. Instituto Nacional sobre Alcoholismo y Farmacodependencia. San José, Costa Rica.

6. Sadock Sadock Ruiz. Sinopsis de psiquiatria: Ciencias del comportamiento/Psiquiatría clínica. Decimoprimera edición, 2015. 680685.
7. Giardina E. Cardiovascular effects of nicotine. Uptodate, 2015.

8. Sandí L Molina D. Manual para facilitadores en la cesación del tabaco. Instituto sobre Alcoholismo y Farmacodependencia, 2013.

9. Rigotti N. Benefits and risks of smoking cessation. Uptodate, 2015.

10. Rigotti N. Pharmatotherapy for smoking cassation in adults. Uptodate, 2015

11. Park E. Behavioral approaches to smoking cessation. Uptodate, 2015

\section{CONFLICTOS DE INTERES}

Los autores declaran que no existe ningún conflicto de interés. 